\title{
Hysteroscopic evaluation of uterine cavity in cases of infertility and its correlation with transvaginal ultrasound and hysterosalpingography
}

\author{
Padma Shukla*, Kalpana Yadav, Sakshi Mishra
}

Department of Obstetrics and Gynaecology, S.S. Medical College, Rewa 486001, Madhya Pradesh, India

Received: 24 August 2016

Accepted: 24 September 2016

\section{*Correspondence:}

Dr. Padma Shukla,

E-mail: shukladrpadma@gmail.com

Copyright: ( $)$ the author(s), publisher and licensee Medip Academy. This is an open-access article distributed under the terms of the Creative Commons Attribution Non-Commercial License, which permits unrestricted non-commercial use, distribution, and reproduction in any medium, provided the original work is properly cited.

\section{ABSTRACT}

Background: Infertility is defined as one year of unprotected intercourse without pregnancy. This study was taken up to evaluate the diagnostic accuracy of hysteroscopy in comparison with hysterosalpingography and vaginal ultrasound in the evaluation of the uterine cavity as first line study in the infertile patient.

Methods: A Prospective and comparative study was carried out in the department of Obstetrics and Gynaecology, S.S. Medical College and associated Gandhi Memorial Hospital, Rewa, MP, India in a period of 13 months from August 2014 to September 2015 conducted on 60 subjects.

Results: 60 patients were evaluated with diagnosis of primary and secondary infertility. Hysteroscopy showed alterations in 65\%, predominantly uterine synechiae, chronic endometritis and endometrial polyp. Hysterosalpingography reported a sensitivity of $90 \%$ and a specificity of $100 \%$, with a positive predictive value of $100 \%$ and a negative predictive value of $66.6 \%$. The agreement between the two methods was moderate. The transvaginal ultrasound reported a sensitivity of $51.21 \%$ and a specificity of $100 \%$, the agreement between these two procedures was moderate. There were no complications during hysteroscopy.

Conclusions: We believe that transvaginal ultrasound, hysterosalpingography and hysteroscopy are complementary in the evaluation of the infertile patient but Hysteroscopy can diagnose small intrauterine lesions much more precisely, (compared with HSG and even TVS) and treat them simultaneously. Thus we consider routine hysteroscopy should be included in the evaluation of the infertile couple.

Keywords: Hysteroscopy, Hysterosalpingography, Infertility, Transvaginal ultrasound

\section{INTRODUCTION}

Infertility is defined as one year of unprotected intercourse without pregnancy. ${ }^{1}$ This may be further classified as primary infertility, in which no previous pregnancies have occurred, and secondary infertility, in which a prior pregnancy, although not necessarily a live birth, has occurred. About $90 \%$ of couples should conceive within 12 months of unprotected intercourse. ${ }^{2}$ Subfertility refers to couples who conceive after 12 months of attempted impregnation. ${ }^{2}$

In India, eight to ten million couples are estimated to be childless. According to the Delhi IVF Fertility Research centre, infertility affects one in six couples in India and the recent National Family Health Survey data estimated that $3.8 \%$ of currently married women between 40 and 44 years are childless. ${ }^{3,4}$ But this overall rate hides variations according to social class. In a population study in three Indian states, for example, the overall prevalence in 7000 couples was $24 \%$ in low socio-economic groups and $31 \%$ in higher classes. ${ }^{5}$

Infertility can result from any alteration affecting the proper functioning of both female and male reproductive organs. The main causes of infertility include: Male factor $20 \%-30 \%$, both male and female factors $10 \%-40 \%$, female factor $40 \%-55 \%$, unexplained infertility $10 \%$ $20 \%$. The causes of infertility in the female are ovulatory dysfunction $20 \%-40 \%$, tubal or peritoneal factor $20 \%$ - 
$40 \%$, uterine factors $15 \%-20 \%$ and unexplained $20 \%$ $30 \%$.

Pathologies within the uterine cavity are the cause of infertility in as many as $15 \%$ of couples seeking treatment and are diagnosed in greater than $50 \%$ of infertile patients. ${ }^{6}$

Therefore, the evaluation of the couple with infertility should consistently include an assessment of the endometrial cavity. Uterine cavity abnormalities include endometrial polyps, endometrial hyperplasia, submucous myomas, intrauterine synechiae, and congenital uterine anomalies. $^{7}$

The programmes for investigating infertile couple include a variety of tests: physical examination, lab test, and most of the times radiological and surgical studies.

The diagnostic methods that can be used to evaluate the uterine cavity are the TVS, sonohysterography, HSG, hysteroscopy, the magnetic resonance imaging (MRI) and computed tomography (CT).

Transvaginal ultrasonography is an excellent method for the study of internal genitalia. It identifies endocavity disorders such as fibroids, adenomyosis and polyp which alters normal anatomy of uterus .Transvaginal ultrasound has a $75 \%$ positive predictive value and $96.5 \%$ negative predictive value for intracavitary polyps but a $0 \%$ positive predictive value for intrauterine adhesions. It has a sensitivity of $44 \%$ for uterine malformations. ${ }^{8}$

The HSG is the most widely used technique in the evaluation of the infertile patient, has a major role in the assessment of the tubes and allows evaluation of the uterine cavity indirectly. The HSG has high sensitivity (98\%), but low specificity (39\%), positive predictive value $(69 \%)$ and negative predictive value $(92 \%){ }^{9}$ Inability to discriminate air bubbles, mucous, and debris from true intracavitary pathology may account for HSG's high false-positive rate when compared with hysteroscopy. ${ }^{7,8}$ Other drawbacks include patient's discomfort, use of iodinated contrast, and radiation exposure. ${ }^{7}$

Various authors concluded that although HSG has a major role in the assessment of the tubes, has a secondary role in the evaluation of the uterine cavity, suggesting that the HSG must be replaced by diagnostic hysteroscopy as first-line in the study of infertility. ${ }^{10}$

Hysteroscopy is considered the gold standard for uterine cavity evaluation because it allows for direct visualization. Diagnostic hysteroscopy may be performed in the office using a small-diameter hysteroscope and saline distension, often without need for anesthesia. ${ }^{7}$

To optimize visualization of the endometrial cavity and avoid performing the procedure during early pregnancy, hysteroscopy is typically scheduled during the early- to mid-follicular phase of the cycle.

This study was taken up to evaluate the diagnostic accuracy of hysteroscopy in comparison with hysterosalpingography and vaginal ultrasound in the evaluation of the uterine cavity as first line study in the infertile patient.

\section{METHODS}

A Prospective and comparative study was carried out in the department of Obstetrics and Gynaecology, S.S. Medical College and associated Gandhi Memorial Hospital, Rewa, MP, India in a period of 13 months from August 2014 to September 2015 conducted on 60 subjects.

After taking informed and written consent, a detailed history, general and systemic examination was done. All the cases underwent transvaginal sonography followed by HSG and then hysteroscopy and further management was done according to the abnormality detected.

All married females of 18 to 45 yrs suffering from primary or secondary infertility were included and couples with male factor infertility, women using contraception and women with ovarian or endocrinal cause of infertility were excluded from study.

Transvaginal sonography (TVS) was done after obtaining proper consent. The uterine anatomy and the adnexae were visualized using a $7.5 \mathrm{MHz}$ vaginal probe transducer. The contour of the endometrial stripe was assessed in the midline sagittal plane and the point of maximum thickness of the stripe (ET) was measured on a frozen image at $1.5 \times$ magnification. Appearance of the endometrial stripe was commented upon as either normal or abnormal; a specific note was made of any focal lesion seen in terms of impression of an endometrial polyp, submucous fibroid, intramural fibroid, or suspicion of hyperplasia.

HSG was performed after taking informed consent between day 7 to day 10 of last menstrual period, day 1 being the first day of menstruation Appearance of uterus and tube was commented upon as either normal or abnormal; normal being an inverted triangle with welldefined, smooth contours and spillage of dye from both the fimbrial ends. Specific note was made of any focal lesion seen in terms of impression of congenital abnormalities of uterine shape, luminal filling defects, abnormalities of uterine contour, blocked tubes, blocked cornu or beaded/dilated tubes.

Hysteroscopy was done in endoscopic O.T. on an outpatient basis in the post menstrual phase. The patient was called on an empty stomach. The patient was asked to void before being taken on the operation theatre table. The procedure was done under sedation and with effect 
of local anaesthesia. Tablet misoprostol $400 \mu \mathrm{gm}$ (pervaginum or sublingual) was administered in some cases about two hours prior to the procedure for cervical priming excluding cases with history of asthma, heart disease, epilepsy and glaucoma.

\section{Procedure}

The patient was placed in lithotomy position. After proper Painting, draping and applying Paracervical block with $1 \%$ Lignocaine solution, uterine sound was then introduced in to the cervix to confirm the position of the uterus and measure the uterocervical length.

The hysteroscope was then gently introduced into the cervix. Further advancement inside the cervical canal and uterine cavity was done under vision. Continuous irrigation of the uterine cavity was obtained by raising the cuff pressure to about $100 \mathrm{~mm} \mathrm{Hg}$ and maintaining the same. A systematic examination of cavity was performed starting from fundus of the uterus. To see the right ostium cable was kept on left side. The opposite ostium was visualized by turning the scope to 180 degrees. The fundus was visualized between the two ostia and the scope was withdrawn slowly to see all the four walls of the uterus, by turning light cable to 360 degrees for this purpose. Internal os and cervical canal was seen by slowly withdrawing hysteroscope.

Typically the endocervical canal shows longitudinal folds, papillae, and clefts. The vascular pattern of the normal endocervical canal reveals branching tree like vessels. The internal os appears as a narrow constriction at the top of the endocervical canal. The isthmus is seen as a cylindrical extension above the os. The corpus is a spacious cavity above the isthmus. The central point of mullerian duct fusion is seen projecting down from the fundus as pale white linear area in midline. The cornua occupy either side of this fused area. The tubal ostia are visible at the upper extremities of the fundal cornua and may show great variation in their appearance and angle of entry into the uterine cavity. The uterine mucosa (endometrium) appears smooth and pink white in colour during the proliferative phase. The gland openings appear as white ringed elevations surrounded by net like vessels. During the secretory phase of the cycle, the endometrium is lush and valvety, it protrudes into the cavity irregularly and can be easily mistaken for small polyp. The hue of the secretory endometrium is of magenta colour.

After the procedure, management was done according to the cause identified; the findings were explained to the patient. The patient was sent home after about 4 hours. A course of antibiotic for five days was prescribed. The calculation of the common abnormalities between hysterosalpingography, ultrasonography and hysteroscopy was based on the Kappa coefficient of agreement. The diagnostic values of sensitivity, specificity, positive and negative predictive values and index test validity is calculated from the box $2 \times 2$.

\section{RESULTS}

The total sample consisted of 60 patients diagnosed with primary and secondary infertility, the procedure was successful in all patients. The age ranged from 25-40 years with maximum no. of cases $83.34 \%$ with a marital life of $<10$ years. Of the total 60 patients $56.67 \%$ patients had primary infertility and $43.34 \%$ patients had secondary infertility.

Abnormal hysteroscopy findings were seen in 39 cases $(65 \%)$, Out of which most of the cases were of uterine synechea (18.34\%), inflamed endometrium (11.68\%) and endometrial polyp $(6.67 \%)$ in decreasing order (Table 1$)$.

Table 1: Distribution of cases on the basis of hysteroscopic finding.

\begin{tabular}{|llll|}
\hline SN & Finding & $\begin{array}{l}\text { Number } \\
\text { of cases }\end{array}$ & Percentage \\
\hline 1 & Normal & 21 & 35 \\
\hline 2 & Adhesion & 11 & 18.34 \\
\hline 3 & Strawberry spots & 5 & 8.34 \\
\hline 4 & Calcified lesions & 2 & 3.34 \\
\hline 5 & Cu-T & 3 & 5.0 \\
\hline 6 & Blocked ostea & 3 & 5.0 \\
\hline 7 & Hyperplasia & 3 & 5.0 \\
\hline 8 & Polyp & 4 & 6.67 \\
\hline 9 & Partial Septum & 3 & 5.0 \\
\hline 10 & $\begin{array}{l}\text { RPOCS/ placental } \\
\text { polyp }\end{array}$ & 2 & 3.34 \\
\hline 11 & $\begin{array}{l}\text { Scarred /Atrophic } \\
\text { endo. }\end{array}$ & 2 & 3.34 \\
\hline 12 & Submucosal fibroid & 1 & 1.67 \\
\hline Total & 60 & 100.0 \\
\hline
\end{tabular}

In the present study, TVS showed normal cavity in $65 \%$ of patients of in fertility and $35 \%$ of patients had some pathology in uterine cavity predominantly fibroid, endometrial pathology and $\mathrm{Cu}-\mathrm{T}$ (Table 2).

In the comparative analysis between the TVS and hysteroscopy, the TVS could explain infertility in $52.5 \%$ of cases while hysteroscopy detected $95 \%$ cases. The overall agreement between both methods was moderate (Kappa $=0.414, \mathrm{P}=0.0001)$ and significant correlation between the two with hysteroscopy being a better diagnostic tool $(\mathrm{x} 2=9.633$, $\mathrm{p}$ value- 0.0019$)$. The strength of agreement is considered to be 'moderate' (Table 3 ).

In the present study HSG revelled normal uterine cavity in $65 \%$ of cases while $35 \%$ of cases abnormal in uterine cavity The overall agreement between HSG and hysteroscopy was found to be moderate (Kappa $=0.475$, $\mathrm{P}=0.0001)$. And significant correlation was found with hysteroscopy being a better diagnostic tool $(x 2=9.633, \mathrm{p}$ value - 0.0019). The strength of agreement is considered to be 'moderate' (Table 4). 
Table 2: Distribution of cases on the basis of TVS finding.

\begin{tabular}{|llll|}
\hline SN & Finding & $\begin{array}{l}\text { Number of } \\
\text { cases }\end{array}$ & Percentage \\
\hline 1 & Normal & 39 & 65 \\
\hline 2 & Enlarged uterus & 02 & 3.34 \\
\hline 3 & Small uterus & 03 & 5.0 \\
\hline 4 & $\begin{array}{l}\text { Collection in } \\
\text { endometrial cavity }\end{array}$ & 02 & 3.34 \\
\hline 5 & $\begin{array}{l}\text { Hyperechoic } \\
\text { endometrium }\end{array}$ & 01 & 1.67 \\
\hline 6 & Septate uterus & 01 & 1.67 \\
\hline 7 & Polyp & 02 & 3.34 \\
\hline 8 & Fibroid & 03 & 5.0 \\
\hline 9 & RPOCS & 02 & 3.34 \\
\hline 10 & Cu-T & 03 & 5.0 \\
\hline 11 & PID & 02 & 3.34 \\
\hline Total & & 60 & 100.0 \\
\hline
\end{tabular}

Table 3: Agreement of TVS and Hysteroscopy.

\begin{tabular}{|c|c|c|c|c|}
\hline \multirow{2}{*}{ SN } & \multirow{2}{*}{ TVS } & \multicolumn{2}{|c|}{ Hysteroscopy } & \multirow{2}{*}{ Total } \\
\hline & & Normal & Abnormal & \\
\hline 1 & Normal (39) & 21 & 18 & 39 \\
\hline 2 & Abnormal (21) & 1 & 20 & 21 \\
\hline & & 22 & 38 & 60 \\
\hline
\end{tabular}

Kappa Value $=0.414, \mathrm{p}$ value $=0.0001$ Significant

Table 4: Agreement of HSG and hysteroscopy.

\begin{tabular}{|lllll|}
\hline \multirow{2}{*}{ SN } & \multirow{2}{*}{ HSG } & \multicolumn{2}{l|}{ Hysteroscopy } & Total \\
\cline { 3 - 4 } 1 & Normal (39) & 22 & 17 & 39 \\
\hline 2 & Abnormal (21) & - & 21 & 21 \\
\hline & & 22 & 38 & 60 \\
\hline
\end{tabular}

$\mathrm{p}$ value $=0.0001$, Significant kappa value $=0.475$

The study depicts that hysteroscopy has sensitivity $(95.12 \%)$ and NPV $(90.47 \%)$ than that of TVS $51.21 \%$. and $48.716 \%$ respectively. HSG has sensitivity $(90 \%)$ and NPV (66.6\%). Specificity and PPV (100\%) of all the three modalities are same.

Table 5: Validity of hysteroscopy, HSG and TVS in infertility.

\begin{tabular}{|lllll|}
\hline & Sensitivity & Specificity & PPV & NPV \\
\hline Hysteroscopy & $95.12 \%$ & $100 \%$ & $100 \%$ & $90.47 \%$ \\
\hline TVS & $51.21 \%$ & $100 \%$ & $100 \%$ & $48.71 \%$ \\
\hline HSG & $90 \%$ & $100 \%$ & $100 \%$ & $66.6 \%$ \\
\hline
\end{tabular}

There were no complications such as perforation, infection, bleeding or complete intolerance during hysteroscopy procedure.

\section{DISCUSSION}

The World Health Organization (WHO) recommends HSG alone for management of infertile women. ${ }^{11}$ The explanation for this discrepancy is that HSG provides information on tubal patency or blockage. Office hysteroscopy is only recommended by the WHO when clinical or complementary test (ultrasound, HSG) suggest intrauterine abnormality or after in vitro fertilization (IVF) failure. ${ }^{11,12}$

Nevertheless, many specialists feel that hysteroscopy is a more accurate tool because of the high false-positive and false negative rates of intra uterine abnormality with HSG. This explains why many specialists use hysteroscopy as a first-line routine test for infertility patients regardless of guidelines. ${ }^{13}$

In present study hysteroscopy diagnosed uterine cavity abnormalities in $66.67 \%$ cases of infertility. These three methods evaluate the uterine cavity differently, the TVS and HSG indirectly and hysteroscopy under direct vision. The accuracy of these methods has been widely studied by several international authors.

While comparing the results between hysteroscopy and TVS, later showed abnormal findings correctly in $35 \%$ of cases, and $65 \%$ cases were undiagnosed. The TVS was highly specific $(100 \%)$, but $51.21 \%$ sensitive compared with hysteroscopy (sensitivity $95.12 \%$, specificity $100 \%$ ). Similar to what was found by El- Mazny et al, where transvaginal ultrasound had a low sensitivity of $41.7 \%$ and a high specificity $100 .^{9}$

TVS showed that 21 cases $(35 \%)$ had intrauterine pathology predominantly fibroids, endometrial hyperplasia, polyps and cu-t. Via hysteroscopy 39 patients $(65 \%)$ were diagnosed. The most frequent findings being adhesions, inflamed endometrium and polyp.

Lawrenz et al observed that 2D and 3D serial TVS correctly predicted uterine cavity in nearly $98 \%$ of cases demonstrating high sensitivity and specificity of TVS for detecting intracavitary pathology. ${ }^{14}$ This dissimilarity with recent study could be because TVS was conducted only in 2D mode and not performed serially.

Ragny et al, evaluated the accuracy of TVS, HSG and hysteroscopy compared to pre IVF patients, found that TVS had a sensitivity of $91 \%$, specificity $83 \%$, PPV of $85.4 \%$ and NPV of $90 \%{ }^{15}$ Regarding HSG they found a sensitivity, specificity, PPV and NPV of $98 \%, 94 \%, 95 \%$ and $98 \%$ respectively. The sensitivity of HSG in present study was $90 \%$, specificity of $100 \%$, a PPV of $100 \%$ and NPV of $66.6 \%$. Observation of Dalfó et al coincided with that observed by Ragny, where the HSG has a high sensitivity $81.2 \%$ and specificity $80.4 \%$, with a PPV $63.4 \%$ and NPV $83.7 . \%{ }^{17}$ 
Camuzcuoglu et al observed that HSG has a high sensitivity of $74.6 \%$ and a specificity of $79.5 \%$ with a PPV of $90.4 \%$ and NPV of $54.7 \%$, however, these authors suggest that normal HSG should not rule out the possibility of a hysteroscopy as it adds to information about trophic, inflammatory and infectious changes that may be the cause of poor reproductive prognosis. ${ }^{16}$

Despite some authors reported a high correlation between the findings of the HSG and hysteroscopy and overall agreement of $73 \%$, in this study we found evidence of a strong correlation and a moderate agreement. ${ }^{17}$

Hysteroscopy is the gold standard for evaluation of the uterine cavity. In addition to direct view, it allows to treat the pathologies diagnosed at the same time. In present study $65 \%$ of cases had abnormal uterine cavity during hysteroscopy of which the most frequent pathologies were uterine synechiae, inflamed endometrium and endometrial polyps. Similar to present study Camuzcuoglu et al found that the most common uterine pathologies were synechiae $(25.8 \%)$ and polyps $(20 \%){ }^{16}$ Koskas et al found $40 \%$ of patients with abnormal uterine cavity. ${ }^{18}$ El-Mazny et al evaluated 145 patients, found $33.1 \%$ of patients with uterine pathology, predominantly polyps, submucosal fibroids and uterine synechiae. ${ }^{9}$ In present study results showed that in primary infertility patients the most common uterine pathologies were chronic endometritis and endometrial polyp, whereas in patients of secondary infertility the most common pathology was uterine synaechie.

The diagnostic accuracy of HSG, the TVS and hysteroscopy to detect uterine abnormalities in infertile patient has been discussed by several authors. But it is still a matter of debate whether hysteroscopy should be performed routinely in infertile patients. There are many recommendations, some authors recommend routine diagnostic hysteroscopy, while others limit its use for infertile patients showing intracavitary alterations in the HSG and TVS. ESHRE guidelines indicate that hysteroscopy is unnecessary, unless it is used for confirmation and intrauterine treatment of suspected pathologies in previous studies. ${ }^{18}$

\section{CONCLUSION}

The main problem with hysteroscopy is that it is an invasive procedure. It is not yet clear whether the findings of hysteroscopy in infertile couples increase pregnancy rates. But we believe that there is high rate of infertility because of intrauterine pathology most commonly intrauterine adhesions and inflamed endometrium (as evidenced in our study) and as these pathologies affect fertility of women, and can be easily treated, hysteroscopy should be performed routinely in order to make a diagnosis and early treatment. This could improve the reproductive future of the patient.
Hysteroscopy is a valuable, simple, safe, feasible, highly tolerable, sensitive specific, low risk and minimally invasive method which allows an adequate exploration of the uterine cavity under vision and it also provides information about the cervical canal. In patients with infertility, hysteroscopy provides the possibility of immediate diagnosis, prompt and effective treatment. The safety, ease of proficiency and ease of diagnosis, with diagnostic hysteroscopy has taken over much of a guess work out of clinical diagnosis. It is an excellent tool in diagnosis of Asherman's syndrome, Submucous fibroids, endometrial hyperplasia and chronic endometritis. It is a very helpful technique in patients with foreign bodies, since it can detect their presence, extension and nature, and these can also be removed under visual control with hysteroscope only.

To conclude, however we believe that these three tools are complementary to each other in the evaluation of the infertile patient, each evaluates the uterine cavity differently, with their advantages and limitations. The HSG is useful, but an indirect test for the evaluation of the uterine cavity, TVS also provides information on the status of the ovaries and follicles along with uterine cavity but Hysteroscopy can diagnose, (compared with HSG and even TVS), small intrauterine lesions much more precisely that might affect fertility and treat them simultaneously. Thus office hysteroscopy can be included as a routine procedure to evaluate infertile patients.

\section{ACKNOWLEDGEMENTS}

In this region of Madhya Pradesh pelvic inflammatory disease is very common that lead to primary or secondary infertility in patients i.e. why I decided to evaluate the infertility patients by hysteroscopy, HSG and by Transvaginal sonography. This study was conducted in Shyam Shah Medical College, Rewa. All hysteroscopy of the patients was done by me.

I am thankful to Dr. Kalpana Yadav who helped me in writing the article. Dr. Sakshi Mishra as a postgraduate student did very hard work and helped in analysing the data and collecting all references.

Funding: No funding sources Conflict of interest: None declared

Ethical approval: The study was approved by the Institutional Ethics Committee

\section{REFERENCES}

1. WHO. Manual for investigation and diagnosis of infertile couple, Cambridge, UK. 2000.

2. Gnoth C, Godehardt E, Frank Harmann P. definition and prevalence of infertility and subfertility. Hum reprod. 2005.

3. Dutta S, Guha R. A clinico-anatomical study on the etiological factors pertaining to primary infertility in 
females using some common investigative procedures. J Anat Soc India. 2007;56:14-7.

4. International Institute of population Sciences. National Family Health Survey; 1998-99, India. International Institute of population Sciences, Mumbai, India. 2000.

5. Talwar PP, Goel OP, Murali IN. Prevalence of infertility in different population groups in India and its determinants. ICMR, 1986.

6. Brown SE, Codinton CC, Schnorr JJ. evaluation of outpatient hysteroscopy, saline infusion hysterosnography and HSG in infertile women: a prospective randomized study. FertilSteril, 2000.

7. Dalfo R A, Ubeda B, Ubeda A. diagnostic value of HSG in the detection of intrauterine abnormalities, a comparision with hysteroscopy. AJR Am J Roentgenol. 2004.

8. Soares SR, Barbosa dos reis MM, Camargos AF. Diagnostic accuracy of sonohysterography, TVS and HSG in patient with uterine cavity disease. Fertil Steril. 2000.

9. El-Mazny A, Abou-Salem N, El-Sherbiny W, Saber W. Outpatient hysteroscopy: A routine investigation before assisted reproductive techniques? Fertil Steril®. 2011;95(1):272-6.

10. Shea R, Shah I. infecundity, infertility, and childlessness in Developing Countries. DHS Comparative Reports No. 9. Calverton, Maryland, USA: ORC Macro and the World Health Organization. 2004.

11. Rowe P, Hargreave T, Mellows H. WHO Manual for the Standardized Investigation and Diagnosis of the Infertile Couple, The Press Syndicate of the University of Cambridge, Cambridge, UK, 1993.

12. deSá Rosa e de Silva AC, Rosa e Silva JC, Cândido dos Reis FJ, Nogueira AA, Ferriani RA. Routine office hysteroscopy in the investigation of infertile couples before assisted reproduction. J Reprod Med. 2005;50:501-6.
13. Koskas M, Mergui JL, Yazbeck C, Uzan S, Nizard J. Office hysteroscopy for infertility: a series of 557 consecutive cases. Obstet Gynecol Int 2010;2010:168096.

14. Lawrenz B, Neunhoeffer E, Lessman-Bechle S, Wallwiener D, Fehm T, Becker S. Reveals How Often pathology office hysteroscopy not on transvaginal ultrasound with previously NOTED - to look at two typical reproductive endocrinology patients groups, treats including failed IVF-ET patients. Surg Gynecol. 2010;7:417-21.

15. Ragni G, Diaferia D, Vegetti W, Colombo M, Arnoldi M, Crosignani PG. Effectiveness of sonohysterography in infertile patient work-up: A comparison With transvaginal ultrasonography and hysteroscopy. Gynecol Obstet Invest. 2005;59:1848.

16. Camuzcuoglu H, Yildirim Y, Sadik S, Kurt S, Tinar S. Comparison of the accuracy of the hysteroscopic and hysterosalpingography in evaluation of the uterine cavity in patients with recurrent pregnancy loss With. Surg Gynecol. 2005;2:159-63.

17. Dalfó $A$, Úbeda Úbeda $A B$, Monzon $M$, Rotger R, Ramos R. Diagnostic value of hysterosalpingography in the detection of intrauterine abnormalities: A comparison With hysteroscopy. AJR. 2004;183:1405-9.

18. Koskas M, Mergui J, Yazbeck C, Uzan S, Nizard J. Office hysteroscopy for infertility: A Series of 557 Cases consecutives. Obstet Gynecol Int. 2010;16:8096.

Cite this article as: Shukla P, Yadav K, Mishra S. Hysteroscopic evaluation of uterine cavity in cases of infertility and its correlation with transvaginal ultrasound and hysterosalpingography. Int J Reprod Contracept Obstet Gynecol 2016;5:3843-8. 